\title{
Visión trágica, tradición y desesperanza en tres novelas de Gabriel García Márquez, Álvaro Cepeda Samudio y Héctor Rojas Herazo
}

\author{
Wilfredo Vega Bedoya ${ }^{1}$ \\ Universidad de Cartagena
}

\section{Resumen}

En este estudio se realiza un análisis sociocrítico contrastivo de tres obras: La hojarasca (1955), de Gabriel García Márquez, La casa grande (1962), de Álvaro Cepeda Samudio, y Respirando el verano (1962), de Héctor Rojas Herazo, cuyas escrituras interrogan los valores de la tradición patriarcal y el advenimiento del progreso. Las tres obras ficcionalizan las causales de la decadencia, la soledad y la incomunicación en que se ve inmerso el ser, la familia y la comunidad en el sistema patriarcal.

Palabras clave: visión trágica, tradición, desesperanza, incomunicación, soledad.

\section{Abstract}

This investigation makes a contrastive social criticism analysis on three Colombian literary novels: La hojarasca (1995), by Gabriel Garcia Marquez, La casa grande (1962), by Álvaro Cepeda Samudio, and Respirando el verano (1962), by Hector Rojas Herazo, whose writing make questions on moral values at patriarchal tradition and the advent of progress. Three novels speak on decline causal, loneliness and isolation of human, family and patriarchal community system.

Key words: tragic vision, tradition, hopelessness, isolation, loneliness.

\footnotetext{
${ }^{1}$ Magíster en Literatura Hispanoamericana del Instituto Caro y Cuervo. Docente asistente de tiempo completo del Programa de Lingüística y Literatura de La Universidad de Cartagena. Miembro de CEILIKA (Centro de Estudio e Investigaciones Literarias del Caribe Colombiano -Universidad de Cartagena-Universidad del Atlántico-). e-mail: bedoyaesteban@gmail.com
}

Recibido: Marzo, 2010 - Aprobado: Junio,2010. 
El presente artículo se centra en el análisis de La hojarasca (1955), de Gabriel García Márquez, La casa grande (1962), de Álvaro Cepeda Samudio, y Respirando el verano (1962), de Héctor Rojas Herazo, obras que muestran una relación estrecha en la medida en que interrogan el origen del deterioro, la ruina y la soledad del mundo patriarcal. La primera novela por analizar será La hojarasca, escrita por Gabriel García Márquez en Cartagena (1948-1951) y publicada en 1955. De esta obra, Mario Vargas Llosa (1975), Hélène Pouliquen (1992) y Morkos Meckled (1995), han afirmado que su narración se centra en "la desestabilización de la ideología" del patriciado liberal, representada en la novela por la figura del Coronel. Los tres coinciden en afirmar que, en la obra, el origen de la desestabilización se adjudica a la llegada de la Compañía Bananera a Macondo. La Compañía representa el arribo de un proceso de modernización que trajo consigo la "hojarasca": "un grupo de advenedizos formado por los desperdicios humanos y materiales de los otros pueblos que llegó a Macondo en búsqueda de progreso":

Después de la guerra, cuando vinimos a Macondo y apreciamos la calidad de su suelo, sabíamos que la hojarasca había de venir alguna vez, pero no contábamos con su ímpetu. Así que cuando sentimos llegar la avalancha lo único que pudimos hacer fue poner el plato con el tenedor y el cuchillo detrás de la puerta y sentarnos pacientemente a esperar que nos conocieran los recién llegados. Entonces, pitó el tren por primera vez. La hojarasca volteó y salió a recibirlo y con la vuelta perdió el impulso, pero logró unidad y solidez; y sufrió el natural proceso de fermentación y se incorporó a los gérmenes de la tierra (1984: 38-9).

Ante este grupo de advenedizos es que la tradición (representada en la figura del Coronel) enfatiza su aferramiento a una visión nostálgica del mundo:

Meme estaba derecha y sombría, hablando de aquel pintoresco esplendor feudal de nuestra familia en los últimos años del siglo anterior, antes de la guerra grande [...].

Meme recordaba con tristeza. Se tenía la impresión de que consideraba el transcurso del tiempo como una pérdida personal, como si advirtiera con el corazón lacerado por los recuerdos que si el tiempo no hubiera transcurrido, aún estaría ella en aquella peregrinación que debió ser un castigo para mis padres, pero que para los niños tenía algo de fiesta, con espectáculos insólitos como el de los caballos bajo los 
mosquiteros. Después todo comenzó a moverse al revés, dijo. La llegada al naciente pueblecito de Macondo en los últimos días del siglo, fue la de una familia devastada, aferrada todavía a un reciente pasado esplendoroso, desorganizada por la guerra $[\ldots]$.

Y repentinamente me expliqué el desencanto que se advertía en Meme cuando recordaba el pasado de nuestra casa. Nuestras vidas habían cambiado, los tiempos eran buenos y Macondo un pueblo ruidoso en que el dinero alcanzaba hasta para despilfarrarlo los sábados en la noche, pero Meme vivía aferrada a un pasado mejor $(72,74-6)$.

Es evidente que en la cita anterior quien habla es el narrador omnisciente. La presencia dominante de su voz cumple el papel de redondear la visión nostálgica de la obra (recurso característico de la narrativa de García Márquez). Visión que cuestiona los efectos de descomposición social que generó la guerra grande y el arribo de la Compañía Bananera a Macondo. En cierta forma, esto dos aspectos se muestran como los obstaculizadores de la continuidad de un orden de vida (patriciado liberal) que se mostraba como válido en la configuración de la comunidad. La guerra grande es presentada como quebrantadora de la armonía del "esplendor feudal" que irradiaba la casa del Coronel, un primer germen del resentimiento. Precisamente, son sus efectos, sumados a los traumatismos generados por la presencia de la Compañía bananera, los determinantes en el estado de desilusión:

De pronto, como si un remolino hubiera echado raíces en el centro del pueblo, llegó la compañía bananera perseguida por la hojarasca. Era una hojarasca revuelta, alborotada, formada por los desperdicios humanos y materiales de los otros pueblos; rastrojos de una guerra civil que cada vez parecía más remota e inverosímil (37).

En lo que respecta a los comportamientos de la "hojarasca", se le caracteriza como una masa vulgar, anómica, codiciosa. Encarna la imagen de la asunción principal del progreso por los habitantes de la nación macondiana (colombiana): "Me acordé de Macondo, de la locura de su gente que quemaba billetes en las fiestas; de la hojarasca sin dirección que lo menospreciaba todo, que se revolcaba en sus ciénagas de instintos y encontraba en la disipación el sabor apetecido" (139) 
Si bien la visión nostálgica del mundo es el eje central que articula la evaluación de la obra, la irrupción de la hojarasca-modernizadora será la causal de su mutación hacia lo trágico. Es esta trasformación axiológica la que despliega la relación del sentido de la obra con el epígrafe de Antígona. El Coronel, de manera similar a Antígona, no actuará acorde a rencores ni a los dictámenes de la hojarasca, sino a los valores de su grupo: "familias refugiadas, cuyos miembros se esmeraban en la conservación de sus tradiciones y en las prácticas religiosas como en el engorde de sus cerdos" (73). Son estos los valores que antepone al odio de los pobladores, para brindarle cristiana sepultura al repudiado médico:

\begin{abstract}
Ahora empiezo a creer que de nada valdrá mi compromiso contra la ferocidad de un pueblo, y que estoy acorralado, cercado por los odios y la impenitencia de una cuadrilla de resentidos. Hasta la iglesia ha encontrado la manera de estar contra mi determinación. El padre Ángel me dijo hace un momento: "Ni siquiera permitiré que sepulten en tierra sagrada a un hombre que se ahorca después de haber vivido sesenta años fuera de dios. A usted mismo lo vería nuestro señor con buenos ojos si se abstiene de llevar a cabo lo que no sería una obra de misericordia, sino un pecado de rebeldía". Yo le dije: "Enterrar a los muertos, como está escrito, es una obra de misericordia". Y el padre Antonio dijo: "Sí. Pero en este caso no nos corresponde hacerla a nosotros sino a la sanidad". [...] No lo hago por mí. Tal vez no sea tampoco por la tranquilidad del muerto. Apenas para cumplir con un compromiso sagrado (59-60).
\end{abstract}

En la novela se asume que el proceso de modernización que vivió Macondo no fue más que el producto efímero de otra forma de explotación ejercida por esta compañía y que con su partida dejó a los habitantes contemplando su estado de postración, de estancamiento:

Para entonces, la compañía bananera había acabado de exprimirnos, y se había ido de Macondo, con los desperdicios de los desperdicios que nos había traído. Y con ellos se había ido la hojarasca, los últimos rastros de lo que fue el próspero Macondo de 1915. Aquí quedaba una aldea arruinada, con cuatro almacenes pobres y oscuros, ocupada por gente cesante y rencorosa, a quien atormentaba el recuerdo de un pasado próspero y la amargura de un presente agobiado y estático (157). 
Es de destacar la manera cómo, desde distintos niveles, se estructura en la obra la contrastación tradición-modernidad, y el tratamiento de los personajes, principalmente el contraste entre el Coronel y el Médico. El Médico representará el hastío de Europa, el escepticismo ante la crisis de la razón. Por el contrario, el Coronel será el ser lúcido de la tradición liberal, cristiana, un ser que aún posee vínculos con el mundo, que aún actúa en pro del bienestar colectivo. Desesperanza y esperanza sentadas en la misma mesa: una manera de pronosticar el advenimiento de la soledad moderna en la provincia comunal:

-Nosotros procuramos salvar el alma, doctor. Esa es la diferencia. Y entonces fui más allá de donde me proponía. Dije: "Usted no lo oye porque es ateo". Y él, sereno, imperturbable: -créame que no soy ateo, coronel. Lo que sucede es que me desconcierta tanto pensar que Dios existe, como pensar que no existe. Entonces prefiero no pensar en eso (138).

La segunda novela por analizar es La casa grande, de Álvaro Cepeda Samudio. En esta obra son legibles dos temáticas: una central que, a diferencia de aquella de La hojarasca, cuestiona los valores patriarcales que oprimen al ser, impidiéndole constituirse libre e independientemente; y una que narra la violencia generada en el pueblo por la llegada de la Compañía Bananera. Ambas temáticas dan cuenta de la visión de desencanto que unifica la obra, y que en cierta medida hace que en la novela la hermana menor, que se constituye en el héroe problemático, asuma una posición trágica como única posibilidad de salida, de sí y de los suyos, ante la fragmentación.

El eje de la novela es el cuestionamiento de los valores dictatoriales que ejerce el Padre frente al pueblo y la familia. En ella se narra la destrucción y la incomunicación que produce en el ser un sistema de valores al interior del cual todo está señalado, elegido y trazado por el patriarca (el padre). Este último representa el absolutismo del poder. Al Padre se le caracteriza como el dueño de las vidas de su familia, de sus empleados y aún del mismo pueblo:

-Él no es de nadie, nunca fue de nadie. A ella no le tiene más consideración de la que te tuvo a ti.

-A mí siempre me trató bien: yo no le di motivos.

-Ninguna le ha dado motivo, ninguna se atrevería a darle motivo.

-No es malo: no es tan malo como dicen.

-Él no es malo: es el dueño de todo y puede tener todo lo que quiera.

-A usted no la pudo tener. 
- ¿Eso dicen?

-Sí, dicen que a usted siempre la ha respetado.

-A mí no me quiso tener (1997: 88).

Se cuestiona radicalmente un orden de vida represivo que sustenta su validez en la continuidad de la tradición y no en la construcción racional de un orden moral y ético del individuo. El orden patriarcal es entendido como un sistema que jerarquiza al ser humano en términos de dinastía y de condición social. En este orden, no es posible la movilidad de la persona debido a que sólo le toca cumplir el papel y ocupar el "lugar natural" que ha sido predeterminado por la tradición. La condición del ser está supeditada al cumplimiento de obligaciones y deberes con el Padre y con la colectividad. Así, los comportamientos se ordenan acorde a unos imperativos categóricos, ya sean eclesiásticos, aristocráticos o militares que no le permiten al sujeto constituirse como individuo. Este sistema, que se ha denominado como patriarcal en el estudio, es el que caracteriza la axiología del patriciado (clase social que ocupa un lugar central en las tres obras). Acerca del patriciado, José Luis Romero expone:

\begin{abstract}
A lo largo del tiempo, el patriciado se fue consolidando gracias a la continuidad de acción de sus sucesivas generaciones, a las fortunas y al poder heredados, a la acción simultánea en diversos sectores de la sociedad, a las alianzas matrimoniales o económicas. Se convirtió en una "antigua riqueza” y comenzó a considerarse y a ser considerado como una aristocracia que, como de costumbre, velaba o idealizaba sus orígenes. Se constituyeron verdaderos linajes, en los que había lugares prefijados para herederos y colaterales, cuya fuerza crecía si habían logrado entroncar con otro colonial que, acaso, lucía blasones nobiliarios (1976: 204).
\end{abstract}

En La casa grande, a diferencia de La hojarasca, no se presenta una visión nostálgica por la desestabilización de la ideología de la casa patriarcal, sino que se expone una visión pesimista frente a la continuidad decadente y a la imposibilidad de superación de la tradición:

El padre supo que podía contar contigo para reconstruir y perpetuar lo que había quedado roto, deshecho, acabado. Lo que no pudo resistir cuando sopló un viento fuerte y acre y podrido y extranjero -que no resistió porque no estaba construido sobre valores perfectamente establecidos sino sobre tradiciones débiles y cansadas- había que reconstruirlo. Reconstruirlo tercamente sobre los mismos carcomidos 
cimientos que habían ya cedido una vez, porque o era muy tarde para cambiarlos o no se conocían ni querían buscarse otros (59-60).

En esta cita de La casa grande se sugiere una respuesta sutil a la toma de posición de La hojarasca. Se expresa como causa de la crisis no a la presencia de otra clase, como la "hojarasca"; tampoco a la presencia de ese "viento fuerte acre y podrido y extranjero" -que es la Compañía Bananera-, sino a las fallas internas en el sistema tradicional, el cual, no obstante, se prolonga. Las fallas se muestran, ante todo, a través del comportamiento del patriarca (el Padre). A la mujer la adquirió como a un caballo (de igual manera que Celia en Respirando el verano), los hijos viven para obedecerlo, los habitantes del pueblo para cumplir sus designios. Todos los que protestan son aniquilados:

Durante cuatro días, en la mañana y en la tarde, se enfrentó con todos y a cada uno lo acusó hasta que los declararon culpables. Debiste oír cosas terribles porque cuando ya supieron que estaban perdidos, que una acusación del padre era suficiente, tuvieron valor para hablar contra él. [...] No supimos lo que dijo el Padre ni lo que hacías tú allí. Pero al cuarto día ustedes habían vuelto más temprano, oímos decir al padre: Esos eran los últimos hemos acabado con ellos. Y luego tú: Y los que quedan, y los hijos de ellos, y los hijos de los hijos, no volverán a intentar una huelga, no se atreverán $(62,64)$.

Es ante esta actitud dictatorial que se enfrenta la hermana menor -el héroe problemático de la obra-, quien establece una negación radical frente a la autoridad del Padre. Por ello comienza su ruptura desacralizando uno de los símbolos más valorados por la tradición, con la "profanación de la virginidad". Este acto connota en la obra una doble ironía: significa, primero, la entrega insensible de la virginidad sin la autorización del Padre, que es el propietario de su vida; y segundo, la persona escogida para la afrenta es uno de los soldados que ha venido a silenciar la protesta de los jornaleros. Es decir, a defender los intereses del Padre:

No tuve necesidad de ir donde las mujeres. En la casa de al lado, te acuerdas, la que estaba cerrada, hay gente. Ella debe vivir ahí porque estaba en el patio, sola en el patio. No le he visto bien la cara. Tampoco habló. Después, un rato después, se puso a llorar, no gritando, sino despacio: casi no se oía que estaba llorando. Yo no entiendo nada, no entiendo nada. Tienes que volver conmigo, tienes que explicarme. No me tocó, 
ni siquiera se agarró de mí, ni siquiera alzó los brazos. Con los ojos abiertos se dejó. No la obligué. No me vas a creer, pero no la obligué. Ella se dejó. No la he visto bien pero es casi de mi alto y olía a cananga. Al principio olía a cananga; después olía a sangre (41).

La hermana menor se configura en un ser crítico que se sacrifica para salvar su integridad. Es el personaje que de manera temprana identifica las ambigüedades del sistema, la voz que le hace caer en cuenta al hermano de que la posibilidad de superación de la fragmentación está ligada al establecimiento de una crítica dialógica. Para ella es claro que en la casa del Padre es imposible hablar de libertad. Opta, entonces, por una salida trágica. La opción de la muerte no es simplemente una forma de escape del sistema; se constituye en una salida de la descomposición de sí y de los suyos. La posibilidad de que sus hijos, producto del desamor, también rompan el cordón umbilical: la dependencia:

Mi hermana ha muerto esta mañana. Ella tenía que morirse. Es duro pero es así: tenía que morirse para lograr un poco de paz en la familia. Ella lo sabía. Sólo era cuestión de tiempo, de esperar a que crecieran un poco, de verlos lo suficiente para no olvidar sus gestos y aprender a distinguirlos de sí misma y poder morirse sin que ellos también se mueran. Pero también era necesario apresurarse para evitar que se acostumbraran mucho a ella, que llegaran a depender de ella de tal modo que luego le fuera imposible morirse.

Ha muerto sola. Desprendida de todo lo que pudiera significar para ella un pretexto para seguir viviendo, para seguir sosteniendo un desafío que no había conducido sino a la destrucción; un desafío que ella no había planteado ni querido, sino que le fue impuesto, sin alternativas: liberada de la tarea de afirmar con su presencia, con su respiración, con la respiración continuada y segura de sus tres hijos, la inutilidad del desafío: desatada, pudo morirse sola $(136,137)$.

El otro personaje que se adentra en la negación del sistema patriarcal es el hermano. Éste se caracteriza como un ser rebelde que muestra de forma temprana su desacuerdo ante a los actos del padre. Él es el primero que parte de la casa, que participa de la lucha de los jornaleros, que acompaña el dolor de la hermana, su cómplice de la infancia. Sin embargo, su lucha se muestra como ambigua en la medida que no alcanza una claridad frente a los hechos. De esta manera, se enfatiza que la violencia, más que dar pie a una reflexión 
que posibilite su comprensión y explicación, lo que ha engendrado es una acción de venganza sustentada en el odio. El ser, al descubrir que no puede distanciarse de los hechos para poder objetivarlos, se halla derrotado, o como se dice en la novela, resignado a una "dura conformidad":

Un cansancio de tener que continuar luchando contra lo que desde el principio se supo que no podría ser derrotado. Porque habría primero que derrotar toda su sangre y el origen de sus manos y su cuerpo dentro de su cuerpo mismo. Y luego disolver todas las vinculaciones que su cuerpo hubiera creado con las gentes de la casa, y esto no era posible. Porque si pudieras ver este cansancio no tendrías ahora que ponerte a esperar que el Hermano diga las palabras que todos sabemos que no va a decir. Que no las dirá aun deseándolo: porque sabe ya que tampoco esta vez podrá derrotar lo que está decidido para ellos: no por el Padre, ni por ti, ni por él, sino por la sangre de ellos y la casa a la que ellos pertenecen. Esto lo sabes tú, lo sabemos todos. Pero quieres que sea el Hermano el que lleve el peso de las palabras que van a ser dichas: quieres que sea él porque tú no tienes ojos para ver su cansancio (72).

Detrás de la ambigüedad de la lucha, también se precisa que el individuo debe entender que la responsabilidad de la fragmentación en la cual se ve inmerso no puede adjudicarse sólo a los demás: a la violencia del Padre, a la matanza de los jornaleros, a la tarea empedernida de la hermana mayor por reconstruir la casa (la casa del Padre), sino que la responsabilidad está ante todo en cada uno de los seres, en la medida en que no se asume una conciencia de los actos, en que no se desarrolla una comprensión de los hechos. Es claro que La casa grande coloca sobre la palestra una de las problemáticas que más ha incidido en la fragmentación de la comunidad colombiana: la imposibilidad de pensar su pasado, lo que ha sido, lo que es posible reivindicar, el cómo generar una transformación, todos aquellos cuestionamientos que le permitirían superar el odio y su consecuente actitud de venganza:

Estoy frente a una nueva derrota: la derrota del cuerpo y de la vida de mi hermana. ¿Derrotada por quién? No ciertamente por el Padre porque ya, aun antes de que él fuera abatido por el odio quieto, maligno, sosegado, que había acumulado a su alrededor con su vida vengativa e implacable, ella lo había derrotado en el momento mismo en que el Padre le rompió la cara con el filo sucio de una espuela; no por la hermana mayor que sintió el nacimiento de cada uno de los hijos como una 
muerte renovada a pesar suyo muy a menudo; no por la casa, ni la familia negada para ella; [...] Y por último, todas las preguntas que no pudieron hacerse cuando la poca y miserable vida de los jornaleros les fue arrebatada a tiros en las estaciones, a lo largo de las vías del ferrocarril, frente a las puertas entreabiertas de sus casas, porque precisamente trataban de ejercer lo que ellos creían, lo que yo principalmente creía, que era su derecho a preguntar, a indagar la razón para la desigualdad y la injusticia. Las preguntas que luego hubo que aplazar porque era más apremiante la tarea de reconstruir y restañar lo que un militar abyecto había tratado de abatir y desangrar. Todas estas preguntas se amontonaban ahora ante la muerte de mi hermana. ¿Dónde encontraré las respuestas? ¿Están acaso en mí? ¿O es su dolorosa y ya definitiva y total respuesta el cuerpo muerto de mi hermana? (142-149).

El cuestionamiento del sistema patriarcal es continuado por los hijos de la hermana menor: ellos son los personajes centrales del capítulo que cierra la obra. Todo el diálogo de "los representantes de la nueva generación" se centra en dilucidar quién ha triunfado: el poder del Padre, la rebeldía de su madre, el odio conforme del hermano, la voluntad de la hermana mayor por reconstruir la morada del patriarca; son sus voces las encargadas de concluir y definir si han alcanzado la libertad de actuar, o si en ellos, al igual que su madre y el hermano, la única opción posible es la autodisolución o una conformidad amarga:

La madre era fuerte. No fue vencida. Cada día de su vida fue una protesta y cada día de su muerte es una victoria. Nosotros somos los derrotados [...]

Es el afán de ella de perdurar su memoria. Aunque odiaba a la madre porque fue la primera que derrotó el odio al desafiar al Padre nos ha criado para que seamos parte de esta casa y de esta sangre y de este odio [...]

El hermano no decidió nada como no decidiremos nosotros; cuando volvió de Bruselas y se unió a los huelguistas lo hizo por odio al padre no por convencimiento $(156,160-1)$.

A través de los hijos se muestra una visión histórica circular, se ilustra una tradición en la cual no hay posibilidad del progreso, sino del retorno. Esto se ejemplifica claramente en la hija de la hermana menor, quien repite la misma afrenta de su madre al profanar también la virginidad de su cuerpo para cuestionar el empeño de la hermana 
mayor por hacerlos parte del Padre (todo aquello que, de manera trágica, había rechazado su madre).

La segunda temática central en la obra es la violencia que generó en el pueblo la Compañía Bananera. A través de ésta se demuestra que el Estado responde a intereses particulares; que, al igual que el Padre, sus actos no están dirigidos a entender los conflictos, sino a silenciarlos. El único cambio es que el castigo no se realiza con la bota del Padre, sino con los fusiles del ejército (los encargados de hacer cumplir la autoridad del Padre-Estado). De esta manera, la opresión del ser se bipolariza entre la casa y la nación, entre una fragmentación interna (el Padre) y un aniquilamiento externo (el Estado).

La última novela por tratar es Respirando el verano, de Héctor Rojas Herazo. En esta obra, como en La casa grande, se señala al sistema patriarcal como el causal del estado de ruina, de soledad y de incomunicación de la casa. Particularmente, la incoherencia del sistema patriarcal se ilustra a partir de la concepción del amor filial. La percepción que se presenta de la mujer es la de un ser sin voz, sometido a una tarea repetitiva de servidumbre y sacrificio. Por medio de las tensiones familiares, se evidencia el grado de dominio y destrucción a que se enfrenta la madre: sus hijos la ignoran, se destruyen y luchan por disputarse la herencia familiar; sus hijas desconocen su palabra, su predicción de la desgracia a la que serán sometidas:

Es duro ver hundirse la casa y oír la voz áspera del hijo que me llama sacudiendo los dedos como si yo fuese una perra [...]

Llegué a creer que mis hijos iban a terminar una de aquellas discusiones matándose unos con otros. La cosa la decidí el día en que Horacio -aullando, lleno de desesperación y de odio contra Jorge- fue a su cuarto y regresó con el revolver en la mano. Cuando Jorge lo vio arrancó de un manotazo el machete que siempre colgaba de la pared del comedor (el mismo con que Mara se hirió el ojo derecho pelando un coco) y -frente a mí, ignorándome- se buscaron maldiciéndose como dos animales. (1962: 162, 167-8).

La concepción del mundo de Respirando el verano tiene mucha relación con la de La casa grande. En ambas novelas se registra la fragmentación del ser bajo el sistema de valores patriarcales que fundamenta su vigencia en la continuidad de una tradición débil y decadente, propiciada por un estado de incomunicación que lleva a 
desconocer, a depender o a destruir a los seres. Será la palabra trágica de Celia -matrona de la casa- la que sentencie la incomunicación y la soledad de sí misma y los suyos:

Yo sabía, algo parecía decírmelo muy adentro, el desenlace que iba a tener este matrimonio. Igual que el de Mara. Pero las dos tercas como una mula no querían ver nada [...] Porque yo he podido verlas sufrir todo aquello como he sufrido tantas otras cosas y quedarme en silencio. Pero el dolor y la decepción me superaron. Quisiera hablar con alguien de esto -como quise hablar una vez de las escapadas a caballo de mi marido y, más tarde de sus apariciones nocturnas y de tantas y tantas cosas que es necesario pacificar y esclarecer-. Pero ahora, a los setenta y seis años, después de gemir y tropezar e inmiscuirme en la vida de los otros, he llegado a la conclusión de que cada existencia hay que vivirla en sí misma. Interior y apretada, sin relación posible con los otros. Porque las palabras no sirven sino para enturbiar y envilecer lo que sentimos. No, las palabras no sirven. Las pronunciamos y quedamos vacíos. Es como si lanzáramos al exterior los desperdicios de lo que pensamos. Porque lo otro, lo que de verdad sentimos o nos disponemos a ejecutar será siempre incomunicable (170).

La incomunicación trágica de Respirando el verano está cercanamente relacionada con la contenida en La casa grande. En ambas, con excepción del periodo de la infancia, no hay comprensión, reflexión o transformación de los seres. El peso de la tradición los resigna a la disolución, al aislamiento y a la desesperanza. De esta manera, al final de la novela, los seres se hallan huérfanos, consternados frente a la disolución de la casa, de la familia, del ser. Se presenta la nueva generación (Valerio) abrumada de preguntas ante al vacío del presente:

Y se vio a sí mismo, confuso y lleno de preguntas bajo los árboles. Sintió su alma forastera, el terrible dolor de haber sido encendido, de sentir su sangre, sus hambrientas arterias, su llegada y su instalación en sus vísceras de ahora, su necesidad de salvación y de amor, su búsqueda de una seguridad -no para su cuerpo, no para sí mismo- sino para ese algo más antiguo que la familia, que la tierra, que el tiempo, que ahora había escogido sus brazos, sus ojos, su cuerpo entero para arder en una minúscula fracción y luego reemprender su oscuro y desolado viaje dejándolo a él -lo que ahora era él- destruido, confundido con las raíces, con el polvo de los veranos y la humedad de los inviernos [...]. Sintió el monstruoso castigo 
de una soledad en la que Dios mismo se sentiría acongojado. Porque no era un problema de llegar, de crecer y arraigarse. No era un problema de ver y escoger y luego esperar una consumación. Era algo más hondo, impenetrable y particular: existir, brillar en la luz, tener gestos, acercarse, oler y alejarse luego con hastío, con rencor o con alegría. Pero siempre solitario, insosegado, porque en la tierra no hay casa donde reposar, porque el alma es oscura y su pasión es sombría y nada puede serle familiar ni en nada puede asentar fidelidad ni esperanza (204-5).

El lector se encuentra frente a una novela que, en primer lugar, ubica el origen del deterioro en las acciones de la tradición, para luego, en un segundo momento, ahondar en el drama de la muerte: el interrogar la condición biológica y, por ende, finita del ser humano. Es esta una de las tensiones centrales de la poética de Rojas: aprehender la fragilidad del ser, vivenciar su orfandad; saberse y saberlo nacido para morir. Para Rojas, en la existencialidad, en la cotidianeidad del ser, se hallan los asuntos vitales del escritor:

-¡Deberíamos terminar esto de una vez!

Ella, sin responder, siguió los menudos quehaceres.

El enfermo insistió:

-Nos inyectan, nos soban, no nos dejan tranquilos y todo ¿para qué? [...] Izando su propia voz de un pozo de lodo, dijo trabajosamente:

-Todos lo sabemos, nada me sirve ya ¿por qué no me dejan morir?

Julia se acercó compasiva. Se sentó al borde del lecho, empapó un poco de algodón en un líquido alcanforado y empezó a friccionarle el pecho y las costillas. Sentía bajo su mano, lo palpaba con decisión, el derrumbe de aquella anatomía. Tuvo, incluso, la sensación de estar lavando un cadáver (145-6).

Toda esta fragmentación termina en una exclamación trágica de Celia a la Divinidad. Desgarrada, interroga su ser "sacrificado", condenado a la absoluta soledad. La exclamación de Rojas se orienta hacia el periplo del hombre en la existencia:

Nos hinchamos nueve meses con el hijo y lo esperamos y llega. Lo parimos y lo criamos con sufrimiento y después lo vemos crecer y sentimos alegría. Sabemos que ha de morir pero esperamos que sea después de nosotros. Los padres (se volvió a Julia que la escuchaba en la actitud ensimismada de quien está rezando) nunca esperamos asistir al entierro de nuestros 
hijos. Tu padre murió primero. Yo lo enterré a él y a dos hijos más y sé muy bien que voy a enterrar a éste (señaló al enfermo que, desmantelado y apacible, respiraba entre la atmósfera color de yodo). Todo parece inútil -la anciana enjugó sus ojos con el extremo de su saco de florecitas estampadas- nacer, tener hijos, vivir, todo es inútil. Volvió su mirada con angustia hacia arriba, hacia las vigas que lloraban atravesadas por las lanzas del verano, e interrogó:

- ¿Para qué nos traes, Dios mío?, ¿dime qué quieres de nosotros? (148).

En conclusión, las tres novelas se interrogan acerca de la decadencia del mundo patriarcal. En éstas se presenta una semejanza en cuanto que narran un desencanto frente al deterioro de un orden que se proyectaba como esperanzador, pero que desembocó en una decadencia absoluta. La gran diferencia en sus tomas de posición se presenta en que, mientras en La Hojarasca se adjudica, principalmente, la degradación del orden comunal a los procesos de modernización establecidos abruptamente en Macondo, en La casa grande y Respirando el verano la decadencia se asigna a la continuación de un orden fundamentado en valores patriarcales que no permitieron la consolidación del ser, sino que, por el contrario, lo fragmentaron y lo negaron como tal.

Rojas Herazo y Cepeda Samudio encuentran queel origen del deterioro social no se ubica en factores externos, sino en los determinantes internos de la organización del sistema patriarcal. En Respirando el verano, la incomunicación, la condición finita-biológica del ser y la orfandad de Dios, nutren la condición trágica del héroe problemático (Celia). En La casa grande, el héroe problemático (la hermana menor) asume que no hay apertura alguna hacia el futuro, por lo cual asume la muerte como única opción de trascender la reificación del mundo. En La hojarasca también se termina asumiendo una salida trágica, pero como producto del salvaje desplazamiento al que ha sido sometida la tradición. Ante este hecho, en primera instancia, el Coronel presenta una visión nostálgica orientada en cierta forma hacia la evocación del esplendor del pasado, pero un pasado que, al hallarse quebrantado (ya sea por la guerra o por la hojarasca), da paso a una posición trágica del mundo. En La casa grande, por su parte, no hay presencia alguna de nostalgia. No se le reconoce validez alguna a la tradición y, por consiguiente, se hace énfasis en la inevitabilidad de la muerte.

Un punto más de encuentro entre La hojarasca y La casa grande es el desengaño manifestado frente a un proceso de modernización 
(representado por la Compañía Bananera) que proyectaba el desarrollo de la región, pero que resultó ser, además de efímero, otra forma de explotación. La introducción de la temática de la Compañía Bananera es utilizada por ambos autores para evaluar el proceso de modernización como el causante mayor de la desviación del proyecto de la modernidad a su simple instrumentalización. Mientras que Héctor Rojas Herazo no parte de la explicación del asentamiento de este proceso, sino que señala en especial, a través del desencanto vivenciado por Celia frente a la contaminación del mar -contaminación que expulsa a sus nietos del reencuentro con "el mar de la infancia"-, cómo dicho proceso desencadenó la destrucción del ambiente natural. Tomas de posición de estos tres autores caribeños en la lucha por legitimar la validez de su nombramiento de la realidad.

\section{Bibliografía}

Bourdieu, P. (1995). Las reglas del arte. Barcelona: Anagrama. . y Waquant, L. (1995). Respuestas por una antropología reflexiva. México: Grijalbo.

Cárdenas Páez, A. (1996). "Escritura y visión de mundo en la narrativa de Rojas Herazo", Cuadernos de literatura, vol. II, nº 3 (Enero-Junio), Bogotá, Pontificia Universida Javeriana. . (1993). "Universo sincrético en Celia se pudre", Historia y Cultura, vol. I, $\mathrm{n}^{\circ} 1$ (Abril), Cartagena, Universidad de Cartagena.

Cepeda Samudio, A. (1997). La casa grande. Bogotá. Panamericana. Chiampi, I. (1983). El realismo maravilloso. Caracas: Monte Ávila.

García Márquez, G. (1984). La hojarasca. Bogotá: Círculo de Lectores.

García Usta, J. (Comp.). (1994). Visitas al patio de Celia: crítica a la obra de Héctor Rojas Herazo. Medellín: Lealón.

(1998). “Celia se pudre, el fin de la saga”. En Celia se pudre. Bogotá: Ministerio de Cultura.

Goldmann, L. (1975). Para una sociología de la novela. Madrid: Ayuso.

Jaramillo Vélez, R. (1994). Colombia, la modernidad postergada. Bogotá: Temis.

Lotman, Y. (1988). La estructura del texto artístico. Madrid: Itsmo.

Lukács, G. (1985). El alma y las formas. Teoría de la novela. México: Grijalbo.

Marín Arias, A. (1986). "Héctor Rojas Herazo, el verbo encarnado", Magazín Dominical de El Espectador, $\mathrm{n}^{\circ} 705$, Bogotá, 17 de noviembre.

Meckled, M. (1995). "García Márquez, el patriarca, el extranjero y la historia". En Cobo Borda, J. (Comp.). Repertorio crítico sobre García Márquez. Bogotá: Instituto Carto y Cuervo, vol. I, pp. 415-450.

Pouliquen, H. (1992) "Teoría y análisis sociocrítico", Cuadernos de trabajo, $\mathrm{n}^{\circ} 4$, Bogotá, Universidad Nacional.

Ramírez, I. \& Turruaga, O. (1990). "Entrevista a Rojas Herazo: 'Yo no soy de un pueblo, yo soy de un patio", Magazín Dominical de El Espectador, Bogotá, 4 de febrero. 
Rojas Herazo, H. (1998). Celia se pudre. Bogotá: Ministerio de Cultura. - (s.f.). En noviembre llega el arzobispo. Bogotá: La Oveja Negra. . (1962) Respirando el verano. Bogotá: Faro. . (1976). Señales y garabatos del habitante. Bogotá: Instituto Colombiano de Cultura.

Romero, J. L. (1976). Latinoamérica, las ciudades y las ideas. México: Siglo XXI.

Tatis Guerra, G. (1987). "La escritura como plegaria y compasión del hombre”, Dominical de El Universal, Cartagena, 29 de noviembre.

A.A.V.V. (1994). "Su palabra citada en palabras de otros", Magazín Dominical de El Espectador, n 604, Bogotá, 27 de noviembre.

A.A.V.V. (1968). Sociología de la creación literaria. Buenos Aires: Nueva visión.

Vargas Llosa, M. (1971). Gabriel García Márquez. Historia de un deicidio. Barcelona: Seix Barral.

Williams, R. (1981). Una década de la novela colombiana: la experiencia de los 70. Bogotá: Plaza y Janes. 